Çukurova Üniversitesi Mühendislik Mimarlık Fakültesi Dergisi, 32(4), ss. 175-184, Aralık 2017

Çukurova University Journal of the Faculty of Engineering and Architecture, 32(4), pp. 175-184, December 2017

\title{
Reactive Red 45’in Antep Fıstığg Katı Atığı Üzerine Etkili Gideriminin Araştırılması
}

\author{
Serpil SAVCI ${ }^{* 1}$, Zeynep KARAMAN ${ }^{2}$, Mutlu YALVAÇ ${ }^{2}$ \\ ${ }^{1}$ Bozok Üniversitesi, Mühendislik Mimarlık Fakültesi, Biyosistem Mühendisliği Bölümü, Yozgat \\ ${ }^{2}$ Mersin Üniversitesi, Mühendislik Fakültesi, Çevre Mühendisliği Bölümü, Mersin
}

Geliş tarihi: 23.05.2017

Kabul tarihi: 19.12.2017

$\ddot{O} \mathbf{z}$

Bu çalışmada reaktif bir boyar madde olan Reactive Red 45'in (RR45) Antep fistığı katı atığı (AFKA) kullanılarak adsorpsiyon yöntemiyle giderimi araştırılmıştır. Kesikli deneylerden elde edilen sonuçlar Langmuir ve Freundlich izoterm modellerine denenmiştir. RR45'in AFKA üzerine adsorpsiyonunda Freundlich İzotermine en iyi uyum sağladığı görülmüştür $\left(\mathrm{R}^{2}=0,9969\right)$. Maksimum adsorpsiyon kapasitesi $35.336 \mathrm{mg} / \mathrm{g}$ olarak bulunmuştur. AFKA' nın yüzey morfolojik özellikleri taramalı elektron mikroskobu (SEM, FEIQuanta 450 FEG) ile belirlenmiştir. AFKA'nın sulu çözeltilerden RR45'in gideriminde etkili, kolay elde edilebilir, bir adsorban olduğu tespit edilmiştir.

Anahtar Kelimeler: RR45, Adsorpsiyon, SEM, Endüstriyel atık

\section{Investigation of the Effective Removal of Reactive Red 45 on Pistachio Solid Wastes}

\begin{abstract}
In this study, removal of a reactive dye, Reactive Red 45 (RR45) onto pistachio hull (AFKA) was investigated by adsorption. The results obtained from the batch experiments were calculated for Langmuir and Freundlich isotherm constants. Freundlich Isotherm is the best fitted for adsorption onto AFKA of $\mathrm{RR} 45\left(\mathrm{R}^{2}=0.9969\right)$. Maximum adsorption capacity is found $35.336 \mathrm{mg} / \mathrm{g}$. The surface morphology of the AFKA was examined by a scanning electron microscopy (SEM), (FEIQuanta 450 FEG). AFKA has been found to be an effective, readily available, adsorbent in the removal of RR45 from aqueous solution.
\end{abstract}

Keywords: RR45, Adsorption, SEM, Industrial waste

*Corresponding author (Sorumlu yazar): Serpil SAVCI, serpil.savci@bozok.edu.tr 


\section{GíRiş}

Boyalar bütün dünyada hemen her alanda yaygın olarak kullanılan sentetik ve organik kimyasallardır. Önceki yüzyılda genellikle organik boyalar kullanılırken boya endüstrisindeki hızl gelişmelere bağlı olarak sentetik boyaların kullanımı çok hızlı bir artış göstermiştir.

Sentetik organik boyalar 1856 yılından günümüze tüm dünyada yaygın olarak kullanılan kimyasallardır. Boyalar başta tekstil olmak üzere inşaat, plastik, kağıt, kozmetik vb. endüstrilerin önemli bir girdisini oluşturmaktadır.

Ülkemizde boya üretimi yıllık \%3-4 artış hızı ile yaklaşık 750000-800000 ton civarında gerçekleşmektedir. $\mathrm{Bu}$ miktarın yarısından fazlasını tekstil boyaları oluşturmaktadır [1].

Tekstil endüstrisinde en yaygın kullanılan boyar maddeler direk, küp, kükürt ve reaktif boyar madde sinıflarında yer almaktadır. Uluslararası renk indeksinde yer alan tekstil boyalarının dağılımında reaktif boyalar \%10,4 ile asit ve dispers boyalardan sonra 3. sirayı almaktadır. Buna ek olarak sentezlenen boyar madde sayısı bakımından reaktif boyar maddeler 4. sirada yer almaktadır. Reaktif boyalar içerisinde renklere göre dağılımda kırmızı boyalar \%28,5'lik kısımla birinci sırada bulunmaktadır. Reaktif boyalar azo, antrokinon ve flalosyonin kromofor gruplarını içermektedir. Bazik ortamda tuz kullanılarak uygulanan bu boyalar sıklikla pamuk, yün, ipek ve poliamit boyamasında kullanılmaktadır [1-3].

Sentetik organik kimyasal boyalar üretim aşamasında, uygulama aşamasında ve renkli ürünün kullanılması aşamasında çevreye zarar vermektedir. Boyar madde içeren atık suların sucul ve karasal ekosisteme olan zararlarının yanı sıra insan yaşamı için de tehlikeli ve toksik etkisi bulunmaktadır [4,5]. Bütün bunlardan dolayı tekstil endüstrisi atık sularının renk giderim prosesleri ekolojik açıdan büyük önem kazanmaktadır. Tekstil endüstrisi atık sularının aritılmasında fiziksel, kimyasal [5-8] ve biyolojik [9] arıtım yöntemleri kullanılmaktadır. Adsorpsiyon konvansiyonel metotlar içerisinde en yaygın kullanılan fiziksel bir arıtım yöntemidir. Adsorpsiyon prosesinde adsorban madde türü, miktarı, yüzey alanı, tane büyüklüğü, $\mathrm{pH}$ ve temas süresi gibi parametreler arıtım verimini etkilemektedir. $\mathrm{Bu}$ proseste en yaygın kullanılan adsorban madde aktif karbon olmakla birlikte, aktif karbon üretiminin pahalı olması nedeniyle yeni arayışlar halen devam etmektedir. Son zamanlarda yapılan çalışmalar tekstil atık sularının arıtımında tek bir yönteminin seçilmesinden daha çok kombine sistemlerin oluşturulması yönündedir [10-12].

Tekstil atık sularının adsorpsiyon ile arıtımında aktif karbon yerine daha düşük maliyetli organik maddelerin adsorban olarak kullanılması önemli bir araştırma konusudur. Tarımsal atıklar ile tarımsal ürünleri işleyen endüstrilerden çıkan katı atıklar içerdikleri selülozik yapılardan dolayı potansiyel adsorban madde olma özelliğini göstermektedir. Yapılan çalışmalarda buğday kepeği [13], findık [14-16], fistık [17], zeytin atıkları [18], badem kabukları [19], kayısı çekirdeği [20,21], kiraz sap ve çekirdekleri [22], pirinç kavuzu [23], mısır kılıfı ve mısır koçanı [24,25], şeker kamışı küspesi [26] ve Hindistan cevizi lifi [27] gibi bir çok organik atığın atıksulardan ağır metal ve boyar madde gideriminde kullanılabilirliği araştırılmıştır. Antep fistığ1 (Pistacia vera), sakız ağacıgillerden (Anacardiaceae), kabuklu bir meyvedir. Tahtams1 sert kabuğun üzeri sarı-kırmızı renkli, lifli, yumuşak bir kılıf ile kaplıdır. \%78 nem içeren bu k1lıf sert kabuğa s1k1 bir şekilde bağlıdır [28-31]. Antep fistığı endüstrisinin \%35-45 ile en büyük atığını bu kısım oluşturmaktadır [31,32].

Barreca ve arkadaşları [32] ve Grace ve arkadaşları [30] yapmış oldukları çalışmada Antep fistığı dış kabuğunun gida takviyesi olarak ve ilaç endüstrisinde kullanılabileceğini bulmuşlardır. Bu konu ile ilgili çok az literatür çalışması olduğunu belirtmişlerdir. Türkiye, İran ve ABD'den sonra Antep fistığı üretiminde dünyada üçüncü sırayı almaktadır. Türkiye Antep fistığının yer aldığı iki gen merkezinden birinin içerisinde bulunmaktadır. Ülkemizin Antep fistığı ağaçlarının \%90'1 Gaziantep, Şanlıurfa, Adıyaman, Kahramanmaraş ve Siirt'te bulunmaktadir [33,34]. 
2015 yılında ülkemizde Antep fistığı üretimi 144.000 ton'dur [29]. Haziran-Eylül ayları arasında faaliyet gösteren Antep fistığı tesislerinde yaklaşık 48.000 ile 50.000 ton arasında katı atık oluşmaktadır. $\mathrm{Bu}$ atıklar araziye dökülerek terk edilmekte veya vahşi depolama yöntemlerine göre bertaraf edilmektedir. Antep fistığı işleme endüstrisinin katı atığı hiç bir uygulamada kullanılmamaktadır. Ek olarak bu atığın güçlü antioksidan, antimikrobiyal ve antimutajenik etkiye sahip fenolik bileşikleri içerdiği kanıtlanmıştır [35]. Antep fistığı katı atığının ekonomik bir ürüne çevrildiği bir çalışma henüz bulunmamaktadır.

$\mathrm{Bu}$ çalışmada Antep fistığı endüstrisi katı atıklarının (AFKA) adsorban madde olarak kullanılarak bir tekstil boyası olan Reactive Red 45 'in sulu çözeltiden adsorpsiyon yöntemiyle giderilmesinde kullanımı araştırılmıştır.

\section{MATERYAL VE METOT}

\subsection{Materyal}

AFKA Nizip'te Antep fistığ üreten bir fabrikadan Ağustos 2016'da elde edilmiş ve $+4^{\circ} \mathrm{C}$ 'de saklanmıştır. Şekil 1'de AFKA'nın görseli verilmiştir.

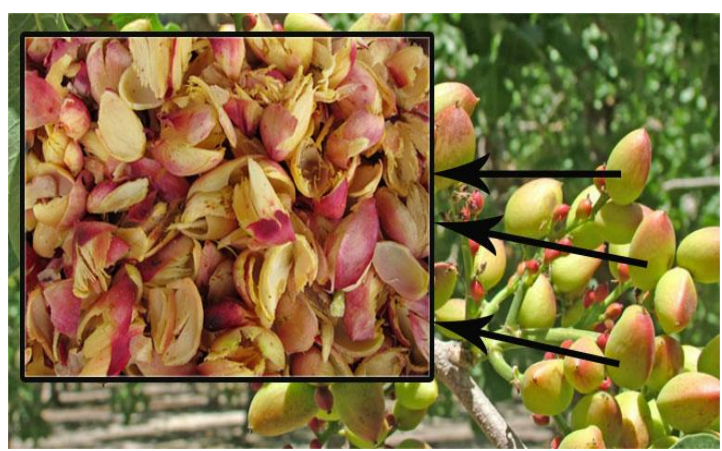

Şekil 1. AFKA'nın görüntüsü

Reactive Red 45 Sigma-Aldrich'ten elde edilmiştir. RR45 boyar maddesi tekstil endüstrisinde yaygın olarak kullanılan bir boyar maddedir. Çizelge 1'de RR45'in kimyasal yapısı ve özellikleri verilmiştir.
Çizelge 1.RR45'in kimyasal yapısı ve özellikleri

\begin{tabular}{|c|c|}
\hline \multicolumn{2}{|l|}{ RR45 } \\
\hline $\begin{array}{l}\text { Molekül } \\
\text { ağırlığ1 } \\
\text { (g/mol) }\end{array}$ & 802.10 \\
\hline Renk & Kırmızı \\
\hline$\lambda \max (\mathrm{nm})$ & 505 \\
\hline Saflik & $<90 \%$ \\
\hline $\begin{array}{l}\text { Kimyasal } \\
\text { Formülü }\end{array}$ & $\mathrm{C}_{27} \mathrm{H}_{19} \mathrm{ClN}_{7} \mathrm{Na}_{3} \mathrm{O}_{10} \mathrm{~S}_{3}$ \\
\hline $\begin{array}{l}\text { Kimyasal } \\
\text { Yapıs1 }\end{array}$ & \\
\hline
\end{tabular}

\subsection{Metod}

\subsubsection{Adsorbanın Hazırlanması}

AFKA, Gaziantep'te bir fabrikadan elde edilmiştir. AFKA, Antep fistığının sert kabuki kısmından ayrılarak saf suda birkaç kez yıkanmıştır. Daha sonra $80^{\circ} \mathrm{C}$ 'de etüvde 48 saat kurutulmuştur. Mixer ile küçük parçalara ayrılarak elenmiştir $[45,46,48]$.

\subsubsection{Boyar Maddenin Hazırlanması}

Adsorpsiyon deneylerinde, reaktif RR45 $(\lambda=505$ $\mathrm{nm})$ boyar maddesi kullanılmıştır. Boyar madde ise Sigma-Aldrich firmasından satın alınmıştır. Boyar madde çözeltileri, saf su kullanılarak 1000 $\mathrm{mg} / \mathrm{L}$ stok boyar madde çözeltisi hazırlanmıştır. Boyar maddelerin, 5, 10, 15, 25, 35 ve $50 \mathrm{mg} / \mathrm{L}$ konsantrasyonlarda hazirlanan standart çözeltilerinin, boyar maddenin maksimum absorbans gösterdiği dalga boyunda absorbansı okunarak kalibrasyon eğrisi çizilmiştir. Adsorpsiyon deneylerinde boyar madde çözeltisinin konsantrasyonu, boyar maddenin konsantrasyon-absorbans grafiğinden hesaplanmıştır.

\subsection{Deneysel Çalışmalar}

AFKA, çeşme suyunda ve saf suda yıkandıktan sonra $80{ }^{\circ} \mathrm{C}$ 'de 2 gün kurutulmuş, 20-30-35-50 ve 
70 mesh eleklerde elenmiştir. RR45 $\left(\mathrm{C}_{27} \mathrm{H}_{19} \mathrm{ClN}_{7} \mathrm{Na}_{3} \mathrm{O}_{10} \mathrm{~S}_{3}\right)$ Sigma-Aldrich firmasindan satın alınmıştır. Reaktif boyar madde herhangi bir saflaştırma yapılmadan kullanılmıştır. Sentetik atıksu $1 \mathrm{~g} / \mathrm{L}$ ' lik stok çözeltinin seyreltilmesiyle elde edilmiştir. Adsorpsiyon çalışmaları madde miktarı aynı olacak şekilde (5g AFKA) ayarlanarak, $1000 \mathrm{~mL}$ ' lik erlende $500 \mathrm{~mL}$ boyar madde çözeltisi kullanılarak mekanik çarkalayıcı (Edmund Bühler GmbH) yardımıyla 100 rpm'de sürekli karışım sağlanarak $25^{\circ} \mathrm{C}$ sıcaklıkta gerçekleştirilmiştir. Langmuir ve Freundlich İzoterm sabitlerinin elde edilmesi amacıyla çeşitli başlangıç boyar madde konsantrasyonları $(25,50$, $75, \quad 100, \quad 300, \quad 500, \quad 700$ ve $900 \quad \mathrm{mg} / \mathrm{L})$ uygulanmıştır. Temas süresi 180 dakikadır. İşlem sonrası kalan boyar madde miktarı, karışımın santrifüjlenerek (6000 rpm, 5dakika) duru fazın spektrofotometrede (Bausch and Lomb, Spectronic 21 model spektrofotometre) ölçülmesiyle bulunmuştur.

Adsorpsiyon çalışmalarında izotermlere, kinetik modellere ve diğer matematiksel modellere olan uygunluk analizleri en düşük kareler regresyonu metodu $\left(\mathrm{R}^{2}\right)$ (lineer) uygulanmıştır [36]. Giderimin yüzdesinin hesaplanması için kullanılan denklem aşağıda verilmiştir:

Giderim $(\%)=\frac{\left(\mathrm{C}_{0}-\mathrm{Ce}\right)}{\mathrm{C}_{\mathrm{o}}} * 100$

Adsorpsiyon izotermleri adsorpsiyon mekanizmasının anlaşılmasında önemli bir parametredir. Langmuir ve Freundlich İzotermleri en yaygın olarak kullanılan modellerdir. Langmuir İzoterm denklemi aşağıda verilmiştir [39].

$\frac{\mathrm{C}_{\mathrm{e}}}{\mathrm{q}_{\mathrm{e}}}=\frac{1}{\mathrm{~K}_{\mathrm{L}}}+\left(\frac{\mathrm{a}_{\mathrm{L}}}{\mathrm{K}_{\mathrm{L}}}\right) \mathrm{C}_{\mathrm{e}}$

$\mathrm{q}_{\mathrm{e}}$ : Adsorbanın birim kütlesinde adsorplanan madde miktarı (mg/g adsorban),

$\mathrm{C}_{\mathrm{e}}$ : Adsorpsiyon sonrası çözeltide kalan maddenin konsantrasyonu (mg/l),

$\mathrm{a}_{\mathrm{L}}$ : Langmuir sabiti $(1 / \mathrm{mg})$,

$\mathrm{K}_{\mathrm{L}}$ : Adsorbatın adsorptivitesine bağlı olan sabit $(1 / g)$.
$\mathrm{Q}_{\max }$ : Adsorbanın maksimum adsorplama kapasitesi (mg/g).

$\mathrm{Bu}$ model Langmuir modelinde bulunan $\mathrm{a}_{\mathrm{L}}$ 'nin qe'nin bir fonksiyonu olarak değiştiği heterojen yüzey enerjileri için özel bir durum ifade etmektedir. Bunun gibi durumlar için Freundlich denklem geliştirmiştir.

$\mathrm{q}_{\mathrm{e}}=\mathrm{K}_{\mathrm{F}} \mathrm{C}_{\mathrm{e}}^{1 / \mathrm{n}}$

$\mathrm{C}_{\mathrm{e}}$ : Adsorpsiyon sonrası çözeltide kalan maddenin konsantrasyonu ( $\mathrm{mg} / \mathrm{l})$.

$\mathrm{q}_{\mathrm{e}}$ : Birim adsorban üzerine adsorplanan madde miktarı (mg/g).

$\mathrm{K}_{\mathrm{F}}$ : Deneysel olarak hesaplanan adsorpsiyon kapasitesi.

n: Adsorpsiyon yoğunluğu.

Yukarıdaki denklemde verilen eşitliğin her iki tarafının da logaritması alınarak doğrusal hale getirilmesiyle aşağıdaki elde edilmiştir.

$\log q_{e}=\log K_{F}+1 / n \log C_{e}$

$\log q_{\mathrm{e}}$ 'nin $\quad \log \mathrm{C}_{\mathrm{e}}$ 'ye karşı değişimi grafiğe geçirilirse $\mathrm{K}_{\mathrm{F}}$ ve $\mathrm{n}$ sabitleri bulunur.

Grafikten elde edilen doğrunun y eksenini kesim noktası $\log \mathrm{K}_{\mathrm{F}}$ 'yi ve eğimi de $1 /$ n'i vermektedir [40].

Bu eşitlikte $K_{F}$ ve $n$ sabitleri sıcaklığa, adsorban ve adsorbat maddeye bağlıdır. n'nin değeri 1'den büyük olmalıdır. $\mathrm{Bu}$ durum $(\mathrm{n}>1)$ adsorpsiyon işleminin elverişli olduğunu göstermektedir [39].

\section{ARAŞTIRMA SONUÇLARI VE TARTIŞMA}

\subsection{AFKA'nın Morfolojik Özelliklerinin Analizi}

AFKA'nın morfolojik özelliklerinin belirlenmesi amaciyla, RR45 adsorpsiyonu öncesi ve sonrasinda taramalı elektron mikroskopuyla (SEM) görüntüleri FEIQuanta 450 FEG cihazı 
kullanılarak belirlenmiş ve Şekil 2-3'de verilmiştir.

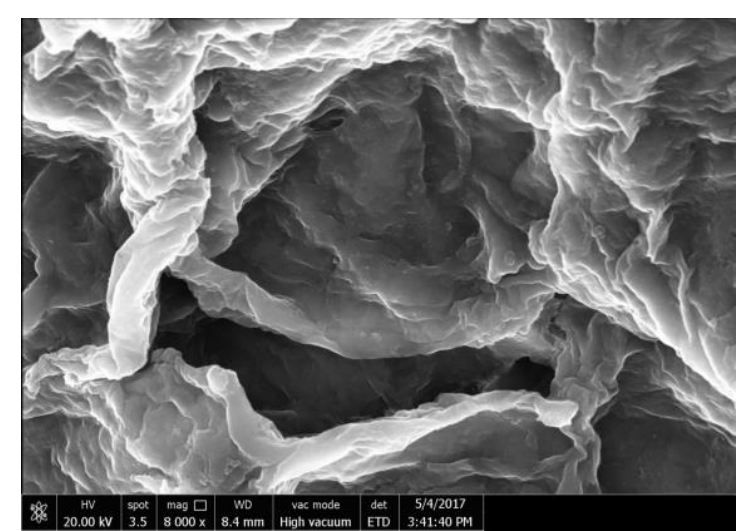

Şekil 2. AFKA adsorpsiyon öncesi (boya yüklenmemiş) SEM görüntüleri

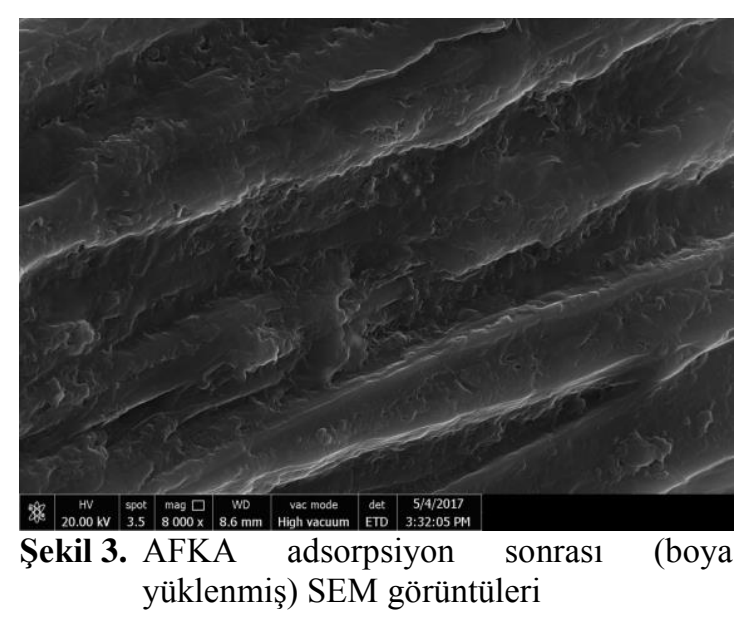

\section{2. pH Etkisi}

Ortam pH'sı hem adsorban yüzeyini hem de adsorban türünü etkileyen en önemli parametrelerden birisidir. Adsorpsiyona pH'ın etkisini araştırmak için diğer değişkenler sabit tutularak 2, 4, 6, 8 ve 10 aralığında değişik $\mathrm{pH}$ değerlerinde AFKA kullanılarak adsorpsiyon çalışmaları yapılmıştır. 50 ppm boya konsantrasyonunda, $25^{\circ} \mathrm{C}$ sicaklikta, 5 g adsorban ilave edilerek, 24 saat süren adsorpsiyon çalışmaları sonunda elde edilen değerler Şekil 4'de verilmiştir. AFKA' nın adsorpsiyon kapasitesi $\mathrm{pH}$ 2'de en yüksek iken, $\mathrm{pH}$ 4'ün üstündeki $\mathrm{pH}$ artışlarında ise sabit kaldığı gözlenmiştir. Şekilde RR45'in AFKA ile adsorpsiyonunda $\mathrm{pH}$ etkisi verilmiştir. Benzer sonuçlar Elkady ve arkadaşlarının [37] yaptıkları yumurta kabuklarıyla reactivered'in giderimi üzerindeki çalışmada adsorpsiyon kapasitesini $46,9 \quad \mathrm{mg} / \mathrm{g}$ olarak bulmuşlardır. Çalışmada $\mathrm{pH} 1$ 'de en iyi giderim veriminin elde edildiğini belirtmişlerdir. Palamthodi ve Lele [38] su kabağ adsorban olarak kullanarak Reactive Red 195-A ve Reactive blue 222 boyar maddelerinin giderimini araştırmışlar ve en iyi giderimin $\mathrm{pH}$ 2'de gerçekleştiğini ifade etmişlerdir.

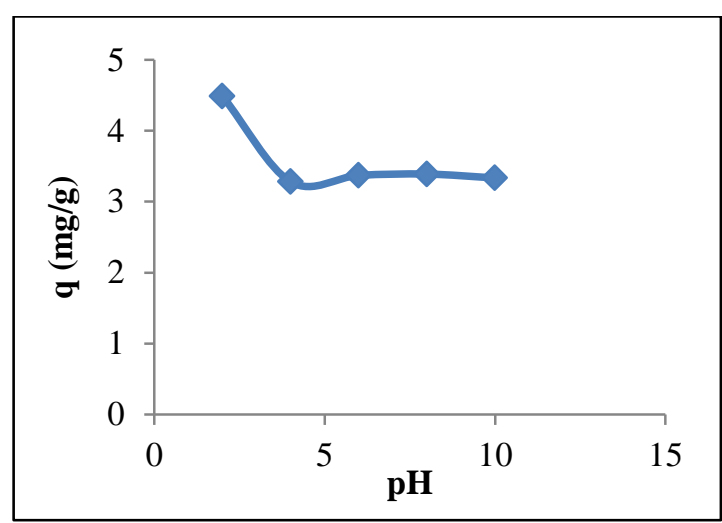

Sekil 4. RR45'in AFKA ile adsorpsiyonunda $\mathrm{pH}$ etkisi $\left(\mathrm{T}=25{ }^{\circ} \mathrm{C}\right.$, adsorban miktarı: $5 \mathrm{~g}$, $\mathrm{t}=24$ saat, $\mathrm{C}_{\mathrm{i}}=50 \mathrm{ppm}$ )

\subsection{Başlangıç Boya Konsantrasyonun Etkisi}

Başlangıç iyon derişimini hesaplayabilmek için önceden hazırlanan 1000 ppm'lik stok çözeltiden farklı konsantrasyonlarda $(100,200,300,400,500$, 600, 700, 800, 900, 1000 ppm'lik RR45 çözeltileri hazırlanmıştır. Çözeltilerin pH's1 2'ye ayarlandiktan sonra toplam hacim $500 \mathrm{~mL}$ 'ye tamamlanacak şekilde hazırlanmıştır. Her bir erlene 5,0 g AFKA ilave edilmiştir. Daha sonra erlenlerin ağızları kapatılarak çalkalayıcıda $24 \mathrm{~h}$ çalkalanmıştır. Bütün deneysel çalışmalar oda sıcaklığında yapılmıştır. Adsorpsiyon sonunda çözeltiler santrifüjlenerek, duru fazın spektrofotometrede konsantrasyonları hesaplanmıştır. Konsantrasyonun adsorpsiyon kapasitesine karşı verilen grafiğinden $700 \mathrm{mg} / \mathrm{L}$ ' den sonra dengeye ulaştığı görülmüştür (Şekil 5). 


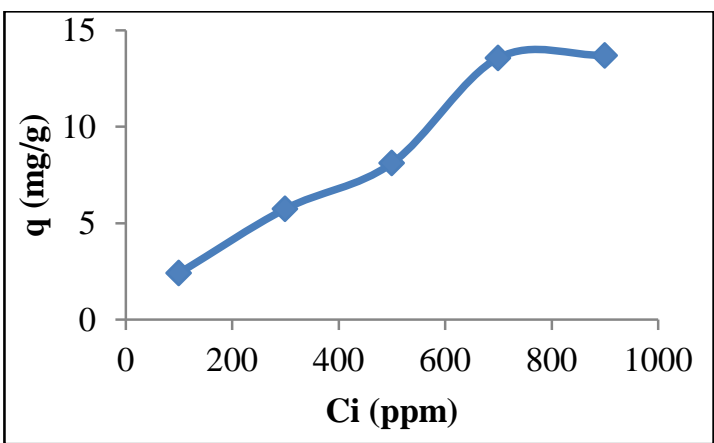

Şekil 5. RR45'in AFKA ile adsorpsiyonunda konsantrasyon etkisi

\subsection{Adsorpsiyon İzotermleri}

Çalışmada Langmuir ve Freundlich izoterm modelleri (Şekil 6-7) denenmiş, çalışmanın Freundlich İzoterm modeline daha iyi uyum sağladığ 1 görülmüştür $\left(\mathrm{R}^{2}=0,9969\right)$.

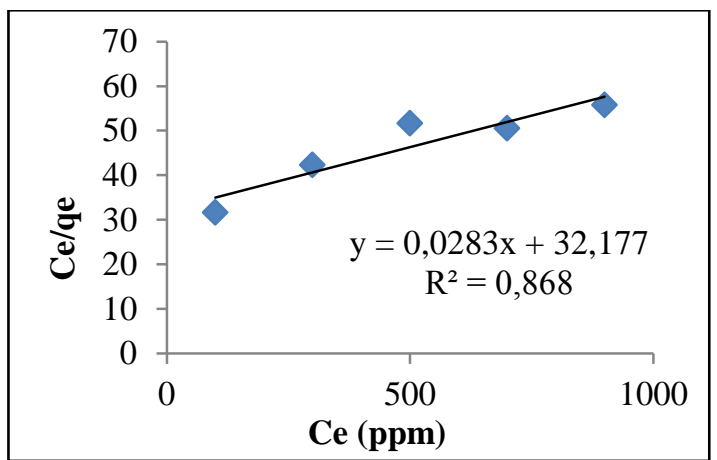

Şekil 6. RR45'in AFKA ile adsorpsiyonunda Langmuir İzotermi

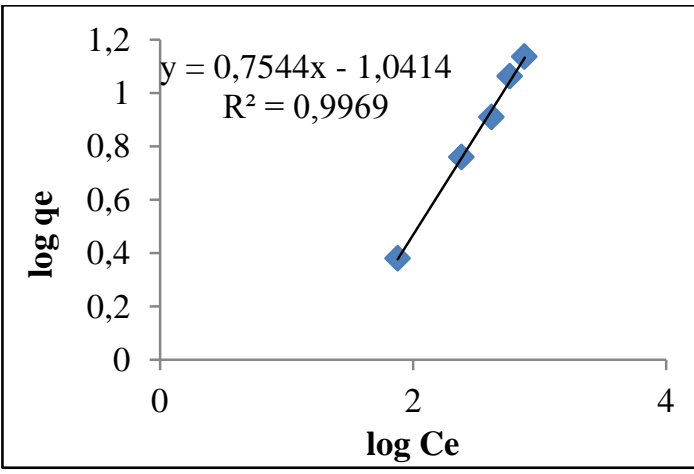

Şekil 7. RR45'in AFKA ile adsorpsiyonunda Freundlich İzotermi
Çizelge 2'de Langmuir ve Freundlich İzoterm modellerinden elde edilen değerler verilmiştir. Çizelge 3'te ise literatürde yer alan çeşitli adsorbanların maksimum adsorpsiyon kapasiteleri bu çalışma ile karşıllaştırılmıştır.

Çizelge 2. Langmuir ve Freundlich İzoterm sabitleri

\begin{tabular}{|l|c|c|}
\hline Langmuir & Parametre (birim) & Değerler \\
\hline & $\mathrm{K}_{\mathrm{L}}(\mathrm{L} / \mathrm{g})$ & 0,031 \\
\hline & $\mathrm{a}_{\mathrm{L}}(\mathrm{L} / \mathrm{mg})$ & 0,0008773 \\
\hline & $\mathrm{Q}_{\max }(\mathrm{mg} / \mathrm{g})$ & 35,336 \\
\hline & $\mathrm{R}^{2}$ & 0,868 \\
\hline $\begin{array}{l}\text { Freundlich } \\
\text { Isotherm }\end{array}$ & $\mathrm{n}_{\mathrm{F}}$ & 1,325 \\
\hline & $\mathrm{K}_{\mathrm{F}}$ & 0,0909 \\
\hline & $\mathrm{R}^{2}$ & 0,9969 \\
\hline
\end{tabular}

Çizelge 3. Çeşitli adsorbanların maksimum adsorpsiyon kapasitelerinin karşılaştırması

\begin{tabular}{|c|c|c|c|}
\hline Adsorban & Boya & $\begin{array}{c}Q_{\max } \\
(\mathrm{mg} / \mathrm{g})\end{array}$ & Referans \\
\hline $\begin{array}{l}\text { Endüstriyel } \\
\text { çamaşırhane } \\
\text { atıksuyundan elde } \\
\text { edilen çamurdan } \\
\text { üretilen aktif karbon }\end{array}$ & RBBR & 33,47 & [41] \\
\hline $\begin{array}{l}\text { Demir grafit } \\
\text { nanokomposit } \\
(\mathrm{Fe} @ \mathrm{G}-\mathrm{N})\end{array}$ & $\begin{array}{c}\text { Acid Red } 88 \\
\text { Direct orange } \\
26 \\
\end{array}$ & $\begin{array}{l}16,9 \\
14,5\end{array}$ & {$[42]$} \\
\hline Pirinç kabuğu & Acid blue 74 & 14,36 & [43] \\
\hline $\begin{array}{l}\text { Pikan cevizi } \\
\text { (Caryaillinoinensis) } \\
\text { zar1 }\end{array}$ & Acid blue 25 & 10,8 & [44] \\
\hline AFKA & RR45 & 35,336 & Bu çalışma \\
\hline
\end{tabular}

\section{SONUÇ VE ÖNERILLER}

Bu çalışmada bir endüstriyel atık olan AFKA'nın reaktif bir boyar madde olan RR45 üzerine adsorpsiyonu kesikli yöntemle çalışılmıştır. Adsorpsiyona etki eden faktörlerden $\mathrm{pH}$ ve başlangıç boyar madde konsantrasyonu çalışılmıştır. Kesikli deneylerden elde edilen sonuçlar izoterm modellerine uygulanmıştır. Langmuir ve Freundlich İzoterm modelleri denenmiş ve RR45'in AFKA ile adsorpsiyonunda en iyi uyum sağlayan izotermin Freundlich İzotermi olduğu tespit edilmiştir. AFKA'nın morfolojik özelliklerinin belirlenmesinde SEM görüntüleri tespit edilmiştir. Adsorpsiyon 
öncesinde AFKA’ nın gözenekli bir yapıda olduğu, adsorpsiyon sonrasında ise bu gözenekli yapının reaktif boyar maddeyi adsorpladığı tespit edilmiştir. Sonuç olarak bir endüstriyel atığın reaktif boyar madde gideriminde etkili bir adsorban olarak kullanılabileceği belirlenmiştir.

\section{KAYNAKLAR}

1. aves.erciyes.edu.tr/ImageOfByte.aspx?Resim= 8\&SSNO=3\&USER=2153-pdf, 15.05.2017.

2. Aspland, J. R., 1997. Textile Dyeing \& Coloration, Published by Amer Assn of Textile, ISBN 10: 0961335017, ISBN 13: 9780961335014

3. Tunçgenç, M., 2015. Türk Boya Sanayisi, İzmir, (2e64676b5be4266_ek-pdf).

4. Ayed, L., Mahdhi, A., Cheref, A., Bakhrouf, A., 2011. Decolorization and Degradation of Azo Dye Methyl Red by an Isolated Sphingomonas Paucimobilis: Biotoxicity and Metabolites Characterization. Desalination 274, 272-277.

5. Robinson, T., Mcmullan, G., Marchant, R., Nigam, P., 2001. Remediation of Dyes in Textile Effluent: a Critical Review on Current Treatment Technologies with a Proposed Alternative. Bioresour. Technol. 77, 247-255.

6. Holkar, C.R., Pandit, A.B., Pinjari, D.V., 2014. Kinetics of Biological Decolorisation of Anthraquinone Based Reactive Blue 19 Using an Isolated Strain of Enterobacter sp. F NCIM 5545. Bioresour. Technol. 173, 342-351.

7. Vandevivere, P.C., Bianchi, R., Verstraete, W., 1998. Treatment and Reuse of Wastewater from the Textile Wet-processing Industry: Review of Emerging Technologies. J. Chem. Technol. Biotechnol. 72, 289-302.

8. Vandevivere, P.C., Bianchi, R., Verstraete, W., 1998. Treatment and Reuse of Wastewater from the Textile Wet-processing Industry: Review of Emerging Technologies. J. Chem. Technol. Biotechnol. 72, 289-302.

9. Paz, A., Carballo, J., José Pérez, M., Domínguez, J.M., 2017. Biological Treatment of Model Dyes and Textile Wastewaters, Chemosphere, 168-177.
10. Forgacs, E., Cserhati, T., Oros, G., 2004. Removal of Synthetic Dyes from Wastewaters: a Review. Environ. Int. 30, 953-971.

11. Santos, D., Andre, B., Cervantes, F.J., van Lier, J.B., 2007. A Review on Current technologies for Decolourisation of Textile Wastewaters: Perspective for Anaerobic Biotechnology. Bioresour. Technol. 98, 2369-2385.

12. Ulson de Souza, Selene Maria Arruda Guelli, Forgiarini, E., Ulson de Souza, A.A., 2007. Toxicity of Textile Dyes and Their Degradation by the Enzyme Horseradish Peroxidase (HRP). J. Hazard. Mater. 147, 1073-1078.

13.Zhang,Y., Huang, G., An, C., Xin, X., Liu, X., Raman, M., Yao, Y., Wang, W., Doble, M., 2017.Transport of Anionic Azo Dyes from Aqu eous Solution to Gemini Surfactant-Modified Wheat Brain: Synchrotron Infrared, Molecular Interaction and Adsorption Studies, Science of the Total Environment, 723-732.

14. Nguyen C., Ahmadpour A., Do D.D., 1995. Effects of Gasifying Agents on the Characterization of Nut Shell-derived Activated Carbon, Adsorpt. Sci. Technol., 247-258.

15. Osvaldo Pezoti Junior, André L. Cazetta, Ralph C. Gomes, Érica O. Barizão, Isis P.A.F. Souza, Alessandro C. Martins, Tewodros Asefa, Vitor C., 2014. Synthesis of $\mathrm{ZnCl}_{2^{-}}$ Activated Carbon from Macadamia Nut

Endocarp (Macadamia integrifolia) by Microwave-Assisted Pyrolysis: Optimization using RSM and Methylene Blue Adsorption Journal of Analytical and Applied Pyrolysis, 166-176.

16. Toles C.A., Marshall W.E., Johns M.M., 1998. Phosphoric Acid Activation of Nutshells for Metal and Organic Remediation: Process Optimization, J. Chem. Technol. Biotechnol., 255-263.

17. Georgin, J., Dotto, G.L., Mazutti, M.A., Foletto, E.L., 2016. Preparation of Activated Carbon from Peanut Shell by Conventional Pyrolysis and Microwave Irradiation-Pyrolysis to Remove Organic Dyes from Aqueous Solutions, Journal of Environmental Chemical Engineering, Issue, 266-275. 
18. Hazzaa R., Hussein, M., 2015. Adsorption of Cationic Dye from Aqueous Solution Onto Activated Carbon Prepared from Olive Stones, Environmental Technology \& Innovation, 36-51.

19. Christopher, T., Wayne, M.E., 2002. Copper İon Removal by Almond Shell Carbons and Commercial Carbons: Batch and Column Studies, Sep. Sci. Technol., 2369-2383.

20. Soleimani, M., Kaghazchi, T., 2008. Activated Hard Shell of Apricot Stones: a Promising Adsorbent in Gold Recovery, Chin. J. Chem. Eng., 112-118.

21. Demirbas, E., Kobya, M., Sulak, M.T., 2008. Adsorption Kinetics of a Basic Dye from Aqueous Solutions Onto Apricot Stone Activated Carbon, Bioresource Technology, 5368-5373.

22. Lessier, M.C., Shull, J.C., Miller, D.J., 1994. Activated Carbon from Cherry Stones, Carbon 30, 1493-1498.

23. Khalil, L.B., 1996. Adsorption Characteristics of Activated Carbon Obtained from Rice Husks by Treatment with Phosphoric Acid, Adsorpt. Sci. Technol., 317-325.

24. Elizalde-González, M.P., Mattusch, J., Wennrich, R., 2008. Chemically Modified Maize Cobs Waste with Enhanced Adsorption Properties Upon Methyl Orange and Arsenic, Bioresour. Technol., 5134-5139.

25. Jothirani, R., Senthil Kumar, P., Saravanan, A., Narayan, A.S., Dutta, A., 2016. Ultrasonic Modified Corn Pith for the Sequestration of Dye from Aqueous Solution, Journal of Industrial and Engineering Chemistry, 162-175.

26. Tahir, H., Sultan, M., Akhtar, N., Hameed, U., Abid, T., 2016. Application of Natural and Modified Sugar Cane Bagasse for the Removal of Dye from Aqueous Solution, Journal of Saudi Chemical Society, 115-121.

27. Namasivayam, C. Sangeetha, D., 2006. Recycling of Agricultural Solid Waste, Coir Pith: Removal of Anions, Heavy Metals, Organics and Dyes from Water by Adsorption Onto $\mathrm{ZnCl} 2$ Activated Coir Pith Carbon, J. Hazard. Mater., 449-452.

28. Tekin, H., Arpacı, S., Atlı, H.S., Açar, İ., Karadağ, S., Yükçeken, Y., Yaman A., 2001.
Antep Fıstığı Yetiştiriciliği (Kitap). Antep F1stığ1 Araştırma Enstitüsü Müdürlüğü, Gaziantep, Yayın No: 13, 132.

29. Antep Fıstığı Yetiştiriciliği, 2010. Milli Eğitim Bakanlığı, Ankara.

30. Grace, M.H., Esposito, D., Timmers, M.A., Xiong, J., Yousef, G., Komarnytsky, S., Lila, M.A., 2016. Chemical Composition, Antioxidant and Anti-inflammatory Properties of Pistachio Hull Extracts, Food Chemistry, 85-95.

31. Açıkalın, K., Karaca, F., Bolat, E., 2012. Pyrolysis of Pistachio Shell: Effects of Pyrolysis Conditions and Analysis of Products, Fuel, 169-177.

32. Barreca, D., Laganà, G., Leuzzi U., Smeriglio, A., Trombetta, D., Bellocco, E., 2016. Evaluation of the Nutraceutical, Antioxidant and Cytoprotective Properties of Ripe Pistachio (Pistacia vera L., variety Bronte) Hulls, Food Chemistry, 493-502.

33. 2011 Y1lı Antep F1stığı Raporu, 2012. T.C. Gümrük ve Ticaret Bakanlığg, Kooperatifçilik Genel Müdürlüğü, Ankara.

34. Ertürk, Y.E., Geçer, M.K., Gülsoy, E., Yalçın, S., 2015. Antep F1stığı Üretimi ve Pazarlamas1, Iğdır Üni. Fen Bilimleri Enst. Der. /Iğdır Univ. J. Inst. Sci. \& Tech., 43-62.

35. Rafiee, Z., Barzegar, M., Sahari, M.A., Maherani, B., 2017. Nanoliposomal Carriers for Improvement the Bioavailability of Highvalued Phenolic Compounds of Pistachio Green Hull Extract, Food Chemistry, 115-122.

36. Berthouex, P.M., Brown, L.C., 2002. Statistics For Environmental Engineers. Lewis Pub., CRC Press, USA, e-book.

37. Elkady, M.F., Ibrahim, A.M., Abd El-Latif, M.M., 2011. Assessment of the Adsorption Kinetics, Equilibrium and Thermodynamic for the Potential Removal of Reactivered Dye using Egg Shell Biocomposite Beads, Desalination, 412-423.

38. Palamthodi, S., Lele, S.S., 2016. Optimization and Evaluation of Reactive Dye Adsorption on Bottle Gourd Peel, Journal of Environmental Chemical Engineering, 4299-4309.

39. Mckay, G., 1996. Use of Adsorbents for the Removal of Pollutions from Wastewater, CRC Press, New York, 186. 
40. Chiou, M.S., Ya-Li, H., 2002. Equilibrium and Kinetic Modeling of Adsorption of Reactive Dye on Cross-Linked Chitosan Beads, Journal of Hazardous Materials, 233-248.

41. Silva, T.L., Ronix, A., Pezoti, O., Souz, L.S., Leandro, P.K.T., Bedin, K.C., Beltrame, K.K., Cazetta, A.L., Almeida, V.C., 2016. Mesoporous Activated Carbon from in Dustrial Laundry Sewage Sludge: Adsorption Studies of Reactive Dye Remazol Brilliant Blue R. Chemical Engineering Journal, 467-476.

42. Konicki, W., Hełminiak, A., Arabczyk, W., Mijowska, E., 2017. Removal of Anionic Dyes using Magnetic Fe@graphitecore-shell Nanocomposite as an Adsorbent from Aqueous Solutions, Journal of Colloid and Interface Science, 155-164.

43. Lakshmi, U.R., Srivastava, V.C., Mall, I.D., Lataye, D.H., 2009. Rice Huskash as an Effective Adsorbent: Evaluation of Adsorptive Characteristics for in Digo Carmine Dye, J. Environ. Manage, 710-720.

44. Hernández-Montoya, V., Mendoza-Castillo, D.I., Bonilla-Petriciolet, A., MontesMorán, M.A., Pérez-Cruz, M.A., 2011. Role of the Pericarp of Caryaillinoinensis as Biosorbent and as Precursor of Activated Carbon for There Moval of Lead and Acidblue 25 in Aqueoussolutions, J. Anal. Appl. Pyrol., 143-151.

45. Yetilmezsoy, K., Demirel, S., Robert J. Vanderbei, 2009. Response Surface Modeling of $\mathrm{Pb}$ (II) Removal from Aqueous Solution by Pistacia Vera L.: Box-Behnken Experimental Desig, Journal of Hazardous Materials 171, 551-562.

46. Deniz, F., Kepekci, R.A. 2016. Dye Biosorption Onto Pistachio by-product: A Green Environmental Engineering Approach, Journal of Molecular Liquids 219, 194-200.

47. dye|World dye variety (09 Aralık 2016).http://www.worlddyevariety.com/reactiv e-dyes/reactive-red-45.htmL.

48. Rastkari, N., Ahmadkhaniha, R., Alemi, R., Afarin, L., 2012. Effect of Chemical Modification on Dye Adsorption Capacity of Pistachio Hull (Book Chapter), Natural and Processed Substances: Production, uses and Effects, 117-127. 
